\title{
The ROLE OF SOCIAL NETWORKING SITES IN EFFECTIVE E-RECRUITMEN; A STUDY OF TELECOM SECTOR IN CONTEXT OF PAKISTAN
}

\author{
Abdul Waheed ${ }^{1 *}$, Miao Xiaoming ${ }^{1}$, Salma Waheed ${ }^{2}$ and Naveed Ahmad ${ }^{1}$ \\ ${ }^{1}$ Management Science \& Engineering, Northwestern Polytechnical University \\ Xi'an, Shaanxi, 710072 - China \\ [e-mail: wahedd_2506@mail.nwpu.edu.cn] \\ [e-mail: miaoxiaoming@nwpu.edu.cn] \\ [e-mail: naveedahmad@mail.nwpu.edu.cn] \\ ${ }^{2}$ School of Psychology, Shaanxi Normal University \\ Xi'an, Shaanxi, 710072 - China \\ [e-mail: salma@mail.nwpu.edu.cn] \\ *Corresponding author: Abdul Waheed
} published August 31, 2019

\begin{abstract}
In cut throat competition, organizations all over the world try to utilize the immense opportunities the Internet has to offer in almost all of their operations. Today, Social networking sites (SNSs) provide utilities designed to help companies to recruit right personnel. Considering the implication of social media for recruitment at infancy stage in Pakistan and lack of studies related to it, this study aims to investigate the role of different SNSs qualities (Easily navigate, Secure process, Eminence Proficiency, Candidate's Attraction and Network Expedition) in effective E-recruitment (EER). Data were collected through structured questionnaire from employees and managers of major telecom companies of Pakistan. Finally, the result of 355 returned and valid questionnaire with 55\% response rate show that the relationship between SNSs qualities and EER is significant. Moreover, results also prove that EER is better than the tradition recruitment and a SNSs comparison show that Facebook is more effective than LinkedIn for EER. The results of this study will help Pakistani companies to develop a successful e-HRM and EER strategy in the current scenario.
\end{abstract}

Keywords: Social Media; Social Networking Sites; e-HRM; E-recruitment; Telecom sector of Pakistan. 


\section{Introduction}

Moving toward the second decade of the 21st century, the use of the Internet has become an integrated and vital tool in today's business world. After SNSs were first created in 1997, many changes have occurred. From being only web-based services that allowed users to simply create a profile, share connections with others, and view their profiles and connections, they emerged to multipurpose individual and business tools [1]. Every day more and more companies enter the digital world by creating their own Facebook page, LinkedIn profile, or a Twitter account. They all have a common goal: to reach as many individuals as possible and make their company more recognizable among the many available. Realistically, to keep up with the developments and intense competition, organizations all over the world try to utilize the immense opportunities the Internet has to offer in almost all of their operations. This is indeed true when it comes to the function of human resource management, and especially when exploring contemporary practices in relation to recruitment and selection. Today, SNSs provide utilities designed to help companies locate and attract applicants while they also enable employers to run instant background checks. However, strangely enough, many corporations avoid the use of social media and fail to take advantage of the opportunities offered [2].

Trying to overcome the barriers imposed by the current financial crisis and constant increasing unemployment rates [3] many people move away from using traditional recruitment channels (i.e., local bureaus, newspapers, radio, television, etc.) and turn to alternative mediums to search for employment opportunities. Today, about one in every six individuals maintain a social network profile on Facebook, while one in every 28 own LinkedIn accounts $[4,5]$. There are many reasons for this recent trend, commonly referred to as e-recruitment [6]. Moreover, with proper preparation and the right procedures in place, SNSs enable companies to run their recruitment strategies at a lower cost [7] and to devote much less time in information processing[7-9], hence making the process more efficient. Despite all the positive outcomes generated through e-recruitment. However, some companies are still hesitant to be involved and adapt to this relatively new practice. Lack of expertise, costs involved, unfamiliarity, and unwillingness to depart from traditional approaches are among the reasons for reluctance. Beyond the aforementioned, however, one important aspect seems to hold back many organizations from pursuing the "e-route." Social profile screening recently generated great controversy regarding its legality as only a hairline segregates information between public and private and crossing it could result in lawsuits. Related to this argument, if network screening is partially illegal and since no restrictions exist to prevent it, then is there any ethical dilemma? Also, inevitably, information screening affects employers' decision to accept or reject an applicant.

The main aim of this study is to classify that either different practices of SNSs (Linkedin and Facebook) leads to effective E-Recruitment in Pakistan or not. Finders suggested that most of the associations have realized the significance of E-Recruitment in Pakistan and have established to take it into practice. The entrance of internet in Pakistan has survived since the early 1990's. The job seekers in Karachi (the most populated city) are focal point on online basis comprehensively to attain high-quality job opportunities. The effortless entrance of internet in universities and offices has facilitated the individual to apply online and submit their resume. Utilization of internet for multiple tasks in multi-national organizations have entirely modified the mind-sets of the Pakistani employers. E-Recruitment is used frequently with the purpose to sustain high level of effectiveness and productivity. Few associations are not in kindness of using the online recruitment expertise due to ancient school of thoughts, 
civilizing peculiarities and other restrictions [10]. Therefore, this study will help Pakistani companies to develop a successful e-HRM strategy in the current scenario.

\section{Theoretical Background}

\subsection{Conventional Recruitment vs. E-Recruitment}

Word Recruitment is defined as a method of magnetizing potential employees and motivating them for applying job in an organization [11]. Difference between conventional Recruitment and E-recruitment is very wide. Conventional recruitment considers as "traditionally recruit employees through newspaper advertisements, trade fairs, and job boards"[12] and E-recruitment define as online sources like job boards, online recruitment sites, and SNSs that proceed as a substitute option [13] described E-Recruitment process occupied companies for recruit emerging talent online.

Alf [12] argued that traditional ways of recruitment (e.g. newspaper advertisements, trade fairs, job boards) will not be sufficient, and new looms will be needed. Du Plessis and Frederick [14] discussed conventional way of recruiting process must be needed to change into e-recruiting process. It offers possibilities to reduce recruitment costs and reach economies of scale. Jobs and talents are becoming more international all the time. Taking account those facts E-Recruitment is effective [15] and financial crises also twist companies towards online Recruitment to look for new opportunities of international recruitment [3]. Researchers investigated those organizations that used e-recruitment achieved lower recruiting costs, round about $87 \%$ of their recruiting costs lower than traditional recruitment $[16,17]$.

\subsection{Social Networking Sites (SNSs) and Effective E-Recruitment (EER)}

E-Recruitment has comprehended the authority of online SNSs and its penetration of worldwide work. In 2011 E-Recruiting demonstrated that 89\% of companies hiring would do so by way of online SNSs a survey exploit of [18]. SNSs such as Facebook and LinkedIn have expanded status in the current years. As long ago as 2010 till 2017, sprawling businesses have required the login documentations for potential employees for prominent SNSs to entire background confirms before hiring.

The application of SNSs in Pakistan is at infancy stage. Along the wide applicability of Facebook in business sector, it was recognized that mainly of the business are not attentive of LinkedIn [19]. Some businesses are attentive of the social network but they do not integrate it in their recruitment and selection process. There is a proportion of business who are using LinkedIn for placement of occupation ads, probable job openings etc. In small, there is a combination of equally conservative and current consumers of expertise in the business of Karachi nowadays [10].A survey by The News Tribe (2012) exposes that Facebook and Twitter is what Pakistanis passionate for! Other SNSs together with Google+, LinkedIn and Pinterest have so far not increased impetus in the country which is considered as one of the greatest rising sites when it comes to Internet exploit.

\subsection{SNSs Qualities}

Abel [20] defined five qualities of SNSs in his study. However, simpler version also has been presented by this study to clarify the views about this study. Qualities of SNSs are considered as an indicator for a satisfactory website and can be adapted to indicators of SNSs. 


\subsubsection{Easily Navigate}

Tong, et al. [21] defined "Ease of navigation" is a procedure to specify functions of a website which can be easy for searcher what he wants to find without any hesitation. A SNS basically regards as an excellent research engine using easily and faster back and forth through the pages [21].

\subsubsection{Secure Process}

As SNSs consider as a trustworthy secure process in which the term Security/privacy, is regarded as an important element [22]. Moreover, the fact that millions of users are on these sites leads to the assumption that certain amount of trust is involved. Dwyer, et al. [23] found out that Facebook users have a greater amount of trust and share more information. But what is about companies? Do they trust Social Networking Sites? Because security/privacy is an important issue in the area of information technology, it is taken into consideration in this study. Security/privacy involves the degree to which the user believes that the site is safe from intrusion and that personal information is protected [21].

\subsubsection{Eminence Proficiency}

The quality of spreading information is one of the art of SNSs that go through the proficiency of manufacture and transports system. It is differentiated by transporting applicable, rationalized information and easy-to-understand information [17]. Lee and Kozar [17] stated in their article that, the higher the worth of the information proficiency, the higher the number of online purchasers will be. Submitting this to SNSs, the higher the Eminence proficiency of information in SNSs, the higher will be the number of users.

\subsubsection{Candidate's Attraction}

El Ouirdi, et al. [24] noted that social media sites seem to be captured attraction of employee in recruitment and selection process. Attractive sites connote towards informative offer highly popular, useful and gorgeous for candidates [25]. recruitment system obliges such sites for job hiring, having more considerations of choice superlative candidate for their organization. On the other hand, famous and attractive SNSs for Recruitment lead to be distinguished among their revivals. In this study, attraction of sites among candidate is deliberated by cataloged users of the SNSs and the status of these sites. Status of the site is calculated by an evaluation of the respondent about the famous of the site among the applicants and whether the site is often argued in the media or not.

\subsubsection{Network Expedition}

Networking Expedition is the scope of the network of social involvements and people participation that is projected to be concerned in this network. Referred to the study, the Network Expedition is defined as the associations which individual have and the network outcome of the site. For businesses it might be significant that the SNS assurances a high level of expensive associations and has a broad Network Expedition. In addition, a SNS makes it easier to attain worldwide contacts (applicants) and therefore, guides to an augmented networking effect. The networking effect is the occurrence whereby a service becomes more expensive as extra people use it, thereby heartening ever-increasing numbers of adopters [26]. The use of SNSs has intensified enormously: LinkedIn, for example needed 16 months to expand its first million users, while the newest million came only within eight days [27]. 


\subsection{Effective E-recruitment (EER)}

Different indicators making EER effective are explored through comprehensive literature review and it includes low cost, get more opportunity, reduced time, fast process, and target group direction as given below:

\subsubsection{Low Cost}

E-Recruitment can be low cost process for posting job and for searching candidates, approximately $90 \%$ lower than the costs used for conventional searching method [28]. Researchers investigated those organizations that used e-recruitment achieved lower recruiting costs, round about $87 \%$ of their recruiting costs lower than traditional recruitment $[16,17]$.

\subsubsection{Get more Opportunity}

E-recruitment process has been supporting for jobseekers worldwide. As, jobseekers have been turning into feasible targets for opportunity as recruiter's dispute by SNS [29]. Scott [30] also analyzed Social networking websites on towards employment opportunities. Transaction of HRM recruitment towards SNS supplied qualified candidate [31] same as it opened a vital opportunity for jobseekers to apply for job post that they want.

\subsubsection{Reduced Time}

Doherty [7] argued in his case study that social networking changed the face of traditional CV for recruitment as HR departments have been limited time, furthermore social recruitment has been in time enhancing the company's recruitment brand. Perfect meaning of time reduction works for e-recruitment. One side, jobseekers just click the button to post their CV for job post, on the other hand, company recruit the best qualified candidate in time. Thus, E-recruitment also reduced the time-to-hire for facilitate online Jobseekers [32].

\subsubsection{Fast Process}

As the world is changing day by day, same as their business strategies are changing. Now, online recruiting is considered as faster and convenient process [33, 34]. More and more candidates are posting their résumé for their better future however e-recruiting has become a fast-growing process for hiring employees [35]. So, it's useful for companies that e-recruitment regards as "a faster posting of jobs, faster applicant response and a faster processing of résumés” [36].

\subsubsection{Target group direction}

Doherty [7] argued that targeted group approach will be helpful for HR in e-recruitment to build constant and personalized relationship with candidates and it's also will be beneficial to avoid happening because clear and specific targeting group will be required. For sprawling business expansion teams also will be considered qualified, high mind and pertinent candidate although they visit target job searcher regularly [28]. 


\section{Proposed Relationships and Study Framework}

SNSs have previously penetrated the recruitment scene and become an important theme in HR departments. The sites, business-oriented or social-oriented networking site, are illustrated by diverse qualities. The selected qualities of the site are: Easily navigate, Secure process, Eminence Proficiency, Candidate's Attraction and Network Expedition. In this paper, the consequence of these qualities on Effective E-Recruitment is experienced. Scheming an Effective E-Recruitment process for magnetizing the best applicants represents a massive confront for institutes. As mentioned in above section, there are traits which make E-Recruitment Effective. The selected traits Low Cost, get more Opportunity, Reduced Time, Extremely Fast Process and Target Group Direction distinguish Effective E-Recruitment. Usually, very modest research has been accomplished on this topic as an entire. Thus, this study is revolutionary and helping to search an answer for the main research questions: "E-Recruitment is efficient as compared to Conventional Recruitment in terms of ease of accessibility and rapidity of response." "There is a strong relationship between Effective E-Recruitment and attributes of Social Networking Sites" and "Maximum Telecommunication Vendor companies in Pakistan prefer E-Recruitment through Social Networking Sites (SNSs) such as Facebook over LinkedIn."

E-Recruitment means online recruitment that is more favorable instead of Conventional recruitment which are linked with newspaper, job board etc. Conventional Recruitments are time consuming and costly work. Companies only highlighting any scrupulous area but in online jobs companies can bring possible candidates not from their own countries but out of countries. So, companies have got much profit from E-Recruitment.

H1: E-Recruitment is efficient as compared to Conventional Recruitment in terms of ease of accessibility and rapidity of response.

H2: Maximum Telecommunication Vendor companies in Pakistan prefer E-Recruitment through Social Networking Sites (SNSs) such as Facebook over LinkedIn.

H3: There is a strong relationship between Effective E-Recruitment (Low Cost, get more Opportunity, Reduced Time, Fast Process and Target Group Direction) and Social Networking Sites qualities (Easily navigate, Secure process, Eminence Proficiency, Candidate's Attraction and Network Expedition).

As H3 is based on proposed relationship between SNSs qualities and EER, therefore, it is represented through a relationship based structural model as shown in Fig. 1 .

Moreover, to validate the SNSs qualities and EER, following research hypothesis are proposed:

\section{SNSs Qualities}

H4: A SNS with easy navigation is better for recruitment.

H5: A SNS with secure processes is better for recruitment.

H6: A SNS with eminence proficiency is better for recruitment.

H7: A SNS having more candidate's attraction is better for recruitment.

H8: A SNS with network expedition is better for recruitment.

\section{Effective E-recruitment (EER)}

H9: E-recruitment with higher degree of effectiveness is measure by cost.

H10: E-recruitment with higher degree of effectiveness is measure by opportunity.

H11: E-recruitment with higher degree of effectiveness is measure by time. 
H12: E-recruitment with higher degree of effectiveness is measure by speed.

H13: E-recruitment with higher degree of effectiveness is measured by target group direction. The final structured model with all conceptual relationship is shown in Fig. 1.

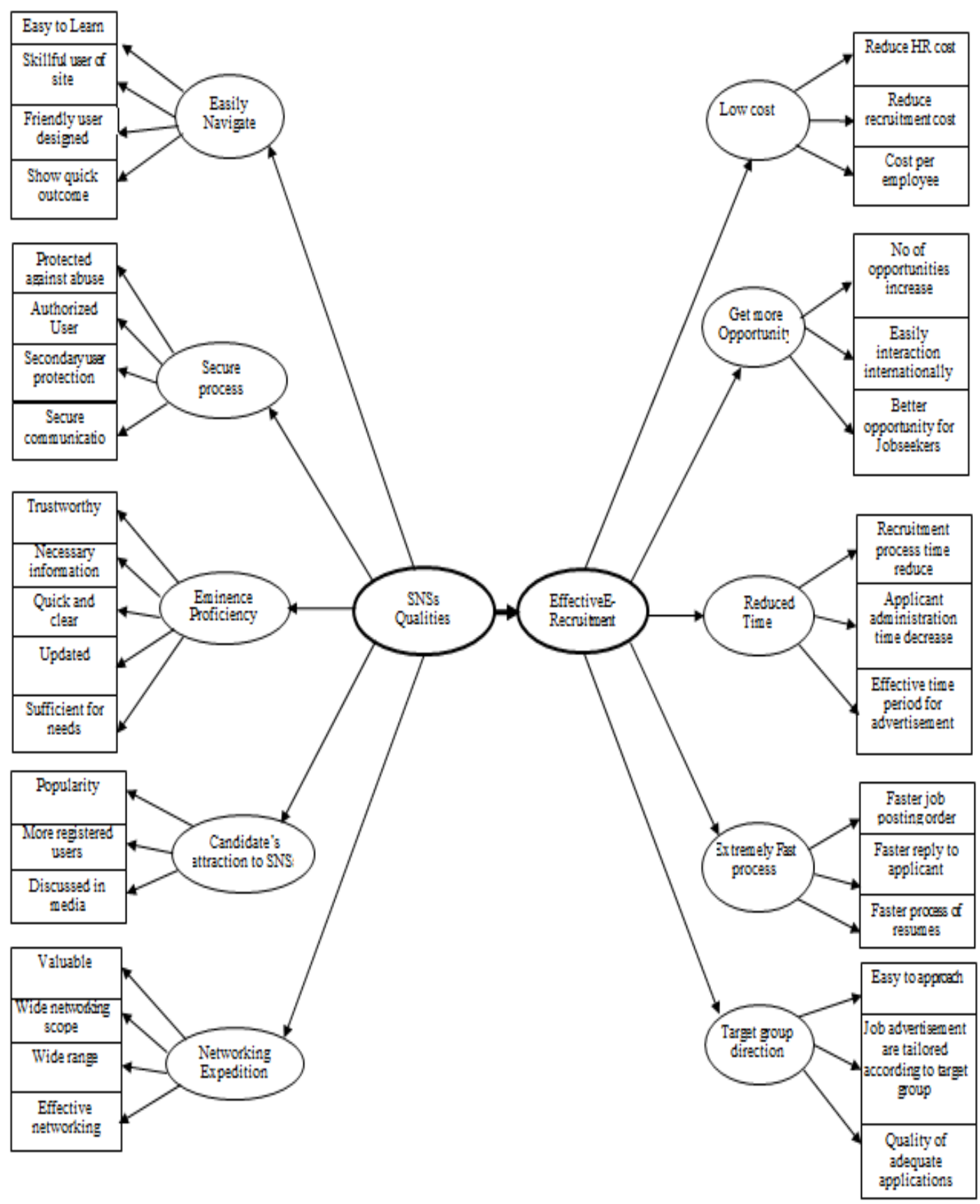

Fig. 1. Conceptual framework 


\section{Methodology}

Qualitative and quantitative information was gathered to get a general and more in-depth insight concerning this research. In general, the combination of a qualitative and a quantitative study as mixed-methods research enhances the reliability and validity of the research cumulatively [37]. Data was collected from the employees and HR Managers of the private telecom organizations. The details of the respondents are given in Table 1. A survey-based questionnaire was developed to get response via emails and the instrument which is used for data collection is the questionnaire and semi-structured interviews. A semi-structured interview allows the interviewer or interviewee to respond in detail on certain aspects that could deviate from the original question and context [38]. The questionnaire was self-constructed. A calculation and reporting of the Cronbach`s alpha coefficient is essential in order to prove the internal consistency reliability for the Likert-type Scale comprised of 1: Strongly agree, 2: Agree, 3: Neutral, 4: Disagree, 5: Strongly Disagree [39]. All the questionnaire instruments were prepared by the different experts working in different organizations. All experts were having experience more than 10 years in their relevant fields. After developing questionnaire, three repetitions were performed to check its contents validity and acceptability. Finally, the data reliability was verified using Cronbach's alpha, which returned values of 0.635 and 0.865 for different variables of study respectively. Acceptable values of Cronbach's alpha are above 0.7 [40]; therefore, the values for the questionnaire indicated satisfactory reliability. In addition, the construct validity of the questionnaire was tested using Spearman rank correlation coefficients, and all of the SNSs qualities and EER sub criteria were correlated, ensuring the construct validity of the questionnaire [41].

After confirming reliability and validity of the questionnaire, it was rotated among the telecom sector in Pakistan. Total 650 questionnaire were randomly distributed through convenient sampling technique. 413 questionnaires were returned back. However, 58 questionnaires were not valid for further analysis due to missing values or in-appropriate filled. Finally, 355 questionnaires were used for analysis presenting 55\% response rate. The details of respondents are given in Table 1.

\section{Developing conceptual model with Structural Equation Modeling (SEM)}

The effect of qualities social networks sites on effective e- recruitment was examined through the maximum likelihood (ML) technique providing aid to the SEM method. The maximum likelihood (ML) technique gives assistances to evaluate unbiased, efficient, and consistent estimates and due to large sample size having the central motive to preferable for ML [42]. The relations among observed variables and latent variables describe by a combination of path analyses and confirmatory factor analyses through SEM method. Observed variables (referred to as sub-criteria) can be directly measured from a five-point Likert scale which typically used by researchers. Latent variables cannot be directly measured; along with observed variables a model must be constructed to measure these variables. Latent variables are further divided into two types: endogenous latent variables and exogenous latent variables. Both endogenous and exogenous variables are indirectly measured by the SEM method. Endogenous variables are dependent variables that can be affected by both endogenous and exogenous variables, whereas exogenous variables are independent variables that can affect other variables. An SEM model consists of two main components: a measurement model and a structural model. The measurement model uses confirmatory factor analysis to determine how well the latent 
variables are measured by the relevant observed variables, whereas the structural model uses regression analysis and path analysis to identify relationships between latent variables.

Table 1. Demographics

\begin{tabular}{|c|c|c|c|c|}
\hline Demographic Items & Frequency & Percent & $\begin{array}{c}\text { Valid } \\
\text { Percent }\end{array}$ & Cumulative \\
\hline \multicolumn{5}{|l|}{ Companies } \\
\hline Mobilink & 70 & 20 & 20 & 20 \\
\hline Ptcl & 80 & 22 & 22 & 42 \\
\hline Telenor & 35 & 9.8 & 9.8 & 52.3 \\
\hline Ufone & 50 & 14 & 14 & 66.3 \\
\hline Warid & 50 & 14 & 14 & 80.3 \\
\hline Zong & 45 & 12.7 & 12.7 & 92.95 \\
\hline Others & 25 & 7 & 7 & 100.0 \\
\hline Total & 355 & 100.0 & 100.0 & \\
\hline \multicolumn{5}{|l|}{ No. of Employees } \\
\hline $500-1000$ & 75 & 21.13 & 21.13 & 21.13 \\
\hline $1000-2000$ & 95 & 26.76 & 26.76 & 47.89 \\
\hline $2000-5000$ & 185 & 52.11 & 52.11 & 100.0 \\
\hline Total & 355 & 100 & 100 & \\
\hline \multicolumn{5}{|c|}{ Employees Experience } \\
\hline Less than 5-month & 35 & 9.85 & 9.85 & 9.85 \\
\hline 5-month to 1-year & 41 & 11.55 & 11.55 & 21.4 \\
\hline 1-year to 5-years & 111 & 31.27 & 31.27 & 52.67 \\
\hline 5 -years to 10 -years & 113 & 31.83 & 31.83 & 84.5 \\
\hline More than 10 years & 55 & 15.5 & 15.5 & 100.0 \\
\hline \multicolumn{5}{|c|}{ Preferred Online Trends } \\
\hline Personal Website & 132 & 37.18 & 37.18 & 37.18 \\
\hline Personal Blog & 52 & 15 & 15 & 52.18 \\
\hline Online Job Board & 80 & 22 & 22 & 74.18 \\
\hline Facebook & 39 & 11 & 11 & 85.18 \\
\hline LinkedIn & 25 & 7.04 & 7.04 & 92.22 \\
\hline Other Social Media & 21 & 6 & 6 & 98.22 \\
\hline Other & 6 & 1.69 & 1.69 & 100.0 \\
\hline Total & 150 & 100.0 & 100.0 & \\
\hline
\end{tabular}

The conceptual measurement model for SNSs qualities consist of five latent variables, i.e., easily navigation, secure process, eminence proficiency, candidate's attraction towards SNSs, network expedition and their observed variables. The conceptual measurement model for effective e- recruitment also consist of five latent variables, i.e., low cost, get more opportunity, reduced time, fast process, target group direction and their observed variables. The conceptual SEM model for the relationship between SNSs qualities and effective e-recruitment, which includes hypotheses H3, is shown in Fig. 1. In this figure, the latent variables are shown in ellipses, and the observed variables are shown in rectangles. 


\section{Results}

The first step of analysis was to check the reliability and validity of the proposed model. Reliability was assessed by using Cronbach's alpha values and validity was assessed by using exploratory factor analysis (EFA), and then further conceptual measurement model for EER and SNSs qualities was verified by using confirmatory factor analysis (CFA). According to Yazdani, et al. [43], exploratory factor analysis (EFA) is made for the complete measurement tool. The results of EFA show that some items did not have statistical significance regarding factor loadings. According to Hulland [44] items with factor loadings of 0.4 or less, are eliminated. The factor loadings of majority of the items are greater than 0.7 indicating the property of items for measuring-related concept. The other coefficient is using to evaluate reliability is Cronbach's alpha (CA). CA is a reliability index which shows the extent of one item belonging to a certain concept [45]. When CA value is 0.7 or greater, the level of reliability is appropriated and good internal consistency for established scales can be measured $[46,47]$. The results for reliability analysis and descriptive statistics are shown in Table 2.

Table 2. Reliability analysis and Descriptive statistics

\begin{tabular}{|c|c|c|c|c|c|c|c|}
\hline Construct & Items & Variable & $\begin{array}{c}\text { Cronbach } \\
\text { s Alpha }(\boldsymbol{\alpha})\end{array}$ & Mean & $\begin{array}{c}\text { Std. } \\
\text { deviation }\end{array}$ & Range & Variation \\
\hline Ease of navigation & 4 & Independent & .820 & 2.5933 & .59327 & 1.75 & .352 \\
\hline Privacy/Security & 4 & Independent & .838 & 2.5167 & .55387 & 2.00 & .307 \\
\hline Information quality & 5 & Independent & .759 & 2.4520 & .45254 & 1.60 & .205 \\
\hline Popularity among applicant & 3 & Independent & .750 & 1.8244 & .34259 & 1.67 & .117 \\
\hline Networking scope & 4 & Independent & .865 & 1.8300 & .34916 & 1.75 & .122 \\
\hline Cost & 3 & Dependent & .715 & 1.8244 & .34259 & 2.00 & .117 \\
\hline Opportunities & 3 & Dependent & .784 & 1.8244 & .34259 & 1.67 & .117 \\
\hline Time & 3 & Dependent & .678 & 1.8244 & .34259 & 2.33 & .117 \\
\hline Fast & 3 & Dependent & .769 & 1.8778 & .31943 & 2.00 & .102 \\
\hline Target group orientation & 3 & Dependent & .635 & 2.4600 & .49255 & 1.33 & .243 \\
\hline
\end{tabular}

By performing IBM SPSS Amos (version 20) software, confirmatory factor analysis (CFA) is using to calculate the conceptual model regarding SNSs qualities and effective e-recruitment firstly. After that manipulation of model has validated by the method of CFA. Given data have been used to manipulate:1) SNSs qualities using five latent variables including easily navigation, secure process, eminence proficiency, candidate's attraction towards SNSs, network expedition; 2) effective e-recruitment using five latent variables including low cost, get more opportunity, reduced time, fast process, target group direction. Any variable able that's not sufficient during the validity process must be omitted. Models of measurement manipulates and modifies still yet goodness-of-fit criteria has been met the correct assessment (listed in Table 2). In addition, the p-value, relative chi-square $(\chi<\mathrm{df})$, goodness-of-fit index (GFI), non-normed fit index (NNFI), comparative fit index (CFI), incremental fit index (IFI), Tucker-Lewis index (TLI), and root mean square error of approximation (RMSEA) techniques apply to check the cogency of the conceptual model in the behave of given data [48]. The satisfactory requirement of all the process is given Table $\mathbf{3}$ which indices modification for both independent and depended variables. After the validation of conceptual models, SEM models use to manipulate by tests hypothesis $\mathrm{H} 3$. 
Table 3. Model Fitness indices

\begin{tabular}{|c|c|l|l|l|l|}
\hline & Indices & & \multicolumn{2}{l|}{ Measurement models } & \\
\hline Sr. & Goodness-of-fit criteria & $\begin{array}{l}\text { Recommended } \\
\text { index values }\end{array}$ & $\begin{array}{l}\text { Qualities } \\
\text { SNSs }\end{array}$ & $\begin{array}{l}\text { Effective } \\
\text { E-recruitme } \\
\text { nt }\end{array}$ & $\begin{array}{l}\text { Final SEM } \\
\text { model }\end{array}$ \\
\hline 1 & p-Value & $0.05 \leq \mathrm{p} \leq 1.00$ & 0.111 & 0.092 & 0.260 \\
\hline 2 & Relative chi-square $(\chi 2 / \mathrm{df})$ & $0 \leq \chi^{2} / \mathrm{df} \leq 2$ & 1.108 & 1.185 & 1.032 \\
\hline 3 & Goodness-of-fit index $(\mathrm{GFI})$ & $0.09 \leq \mathrm{GFI} \leq 1.00$ & 0.952 & 0.993 & 0.907 \\
\hline 4 & Comparative fit index (CFI) & $0.09 \leq \mathrm{CFI} \leq 1.00$ & 0.995 & 0.993 & 0.997 \\
\hline 5 & Incremental fit index (IFI) & $0.9 \leq \mathrm{IFI} \leq 1.00$ & 0.995 & 0.993 & 0.997 \\
\hline 6 & Tucker-Lewis index (TLI) & $0.9 \leq \mathrm{TLI} \leq 1.00$ & 0.992 & 0.996 & 0.997 \\
\hline 7 & $\begin{array}{l}\text { Root mean square error of } \\
\text { approximation (RMSEA) }\end{array}$ & $0 \leq \mathrm{RMSEA} \leq 0.08$ & 0.015 & 0.020 & 0.007 \\
\hline
\end{tabular}

The SEM validator procedure has similarity with measurement conceptual models process (Table 5) by using the goodness-of-fit criteria, suggested catalog digits, and adjustment processes. So, the concluding SEM model and SEM's goodness-of-fit outcomes are given in Table 3 and Fig. 2, correspondingly.

\subsection{Hypothesis 1}

Hypothesis 1 proposed that EER is better than traditional recruitment in the current scenario. Table 2 shows results of comparison between EER and traditional recruitment in different telecom companies of Pakistan. Most of the respondents are disagree (145-respondents) about using EER currently in the organization. Respondents agree about the importance of EER in organization by considering it more valuable (129-respondents), Useful (138-respondents), more preferable (148-respondents), provide more opportunities, and cost effective (132-respondens). More details about comparison of tradition recruitment and EER can be seen in Table 4.

Table 4. Effective E-Recruitment (EER1) vs Conventional Recruitment

\begin{tabular}{|l|c|c|c|c|c|c|c|c|c|c|}
\hline Statements & \multicolumn{1}{|c|}{$\begin{array}{l}\text { Strongly } \\
\text { Disagree }\end{array}$} & \multicolumn{2}{|c|}{$\begin{array}{c}\text { Disagre } \\
\text { e }\end{array}$} & \multicolumn{3}{|c|}{ Neutral } & \multicolumn{3}{c|}{$\begin{array}{c}\text { Agree } \\
\text { Agree }\end{array}$} \\
\hline & $\mathrm{F}$ & $\%$ & $\mathrm{~F}$ & $\%$ & $\mathrm{~F}$ & $\%$ & $\mathrm{~F}$ & $\%$ & $\mathrm{~F}$ & $\%$ \\
\hline $\begin{array}{l}\text { Does your company use conventional } \\
\text { recruitment instead of e- recruitment? }\end{array}$ & 2 & 1.3 & 145 & 95.3 & 3 & 2.0 & 1 & .7 & 1 & .7 \\
\hline $\begin{array}{l}\text { Do you consider social media can bring } \\
\text { value to your job application? }\end{array}$ & 1 & .7 & 8 & 5.3 & 12 & 8.0 & 116 & 77.3 & 13 & 8.7 \\
\hline $\begin{array}{l}\text { Do you think conventional recruitment has } \\
\text { no more useful? }\end{array}$ & 0 & 0 & 1 & .7 & 11 & 7.3 & 116 & 77.3 & 22 & 14.7 \\
\hline $\begin{array}{l}\text { Mostly companies give preference to } \\
\text { E-recruitment. }\end{array}$ & 0 & 0 & 0 & 0 & 2 & 1.3 & 123 & 82 & 25 & 16.7 \\
\hline $\begin{array}{l}\text { Is E-recruitment faster, got more } \\
\text { opportunities and target, reduce cost and } \\
\text { time, now if you compare it to past? }\end{array}$ & 0 & 0 & 2 & 1.3 & 16 & 10.7 & 117 & 78 & 15 & 10 \\
\hline
\end{tabular}




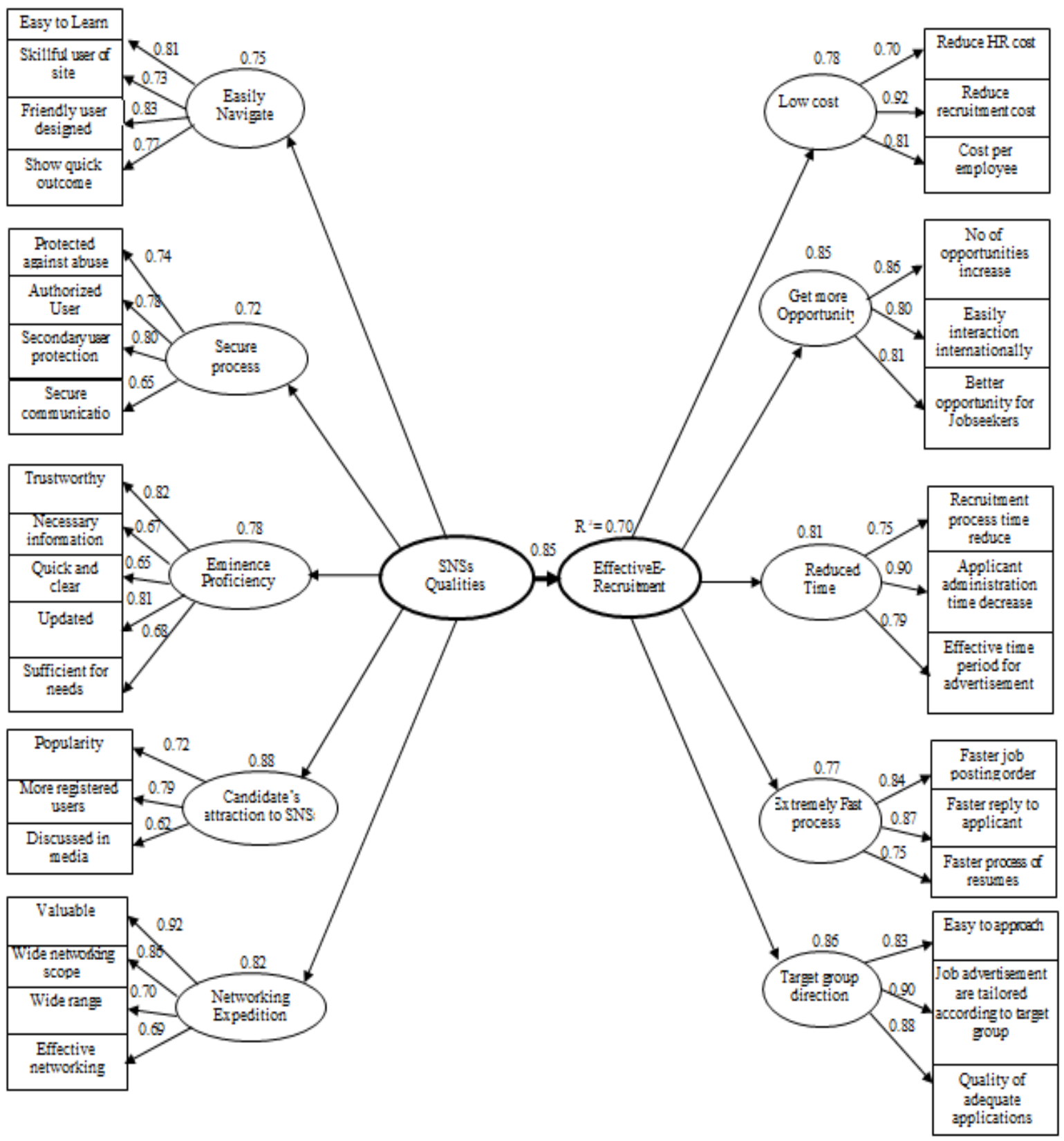

Fig. 2. Results of final structural model

\subsection{Hypothesis2}

Hypothesis 2 proposed that Facebook is a better platform for EER than LinkedIn. Table 3 shows the results for Facebook vs. LinkedIn. Results found that Facebook is better platform considering fit for recruitment (140-respondents), Important site (128-respondents), ads of recruitment (190-respondents). More details about comparison of Facebook and LinkedIn for recruitment is shown in Table 5. 
Table 5. Facebook vs LinkedIn

\begin{tabular}{|l|l|l|l|l|l|l|l|l|l|l|l|}
\hline Questions & \multicolumn{2}{l|}{$\begin{array}{l}\text { Strongly } \\
\text { disagree }\end{array}$} & \multicolumn{2}{l|}{ Disagree } & \multicolumn{2}{l|}{ Neutral } & \multicolumn{2}{l|}{ Agree } & \multicolumn{2}{l|}{$\begin{array}{l}\text { Strongly } \\
\text { agree }\end{array}$} \\
\hline & F & $\%$ & F & $\%$ & F & $\%$ & F & $\%$ & F & $\%$ \\
\hline $\begin{array}{l}\text { Facebook is a best site for } \\
\text { E-recruitment. }\end{array}$ & 6 & 4 & 31 & 20 & 29 & 19 & 84 & 56 & 0 & 0 \\
\hline $\begin{array}{l}\text { Facebook is very important site } \\
\text { for recruitment within next three } \\
\text { years }\end{array}$ & 0 & 0 & 14 & 9.3 & 8 & 5.3 & 119 & 79.3 & 9 & 6 \\
\hline $\begin{array}{l}\text { Did you get your current job by } \\
\text { Facebook? }\end{array}$ & 3 & 2 & 68 & 45.3 & 9 & 6 & 70 & 46.7 & 0 & 0 \\
\hline $\begin{array}{l}\text { Do you mainly use Facebook to } \\
\text { post your little ads or recruitment? }\end{array}$ & 0 & 0 & 22 & 14.7 & 7 & 4.7 & 114 & 76 & 7 & 4.7 \\
\hline $\begin{array}{l}\text { Your company prefers to use } \\
\text { Facebook for E-recruitment as } \\
\text { compare to LinkedIn }\end{array}$ & 9 & 6 & 52 & 34.7 & 19 & 12.7 & 69 & 46 & 1 & .7 \\
\hline $\begin{array}{l}\text { LinkedIn has not much } \\
\text { importance to E-recruitment. }\end{array}$ & 2 & 1.2 & 30 & 20 & 35 & 23.3 & 81 & 54 & 2 & 1.3 \\
\hline
\end{tabular}

\subsection{Hypothesis 3-13}

As hypothesis 3-Hypothesis 13 proposed were proposed to check the role of SNSs quality (easy navigation, secure process, eminence proficiency, candidate's attraction, network expedition) for better recruitment and different indicators contributing to the effectiveness of e-recruitment. H3 proposed the relationship between SNSs qualities and EER. The goodness-of-fit indices criteria have already been evaluated for the measurement models for each model (SNSs qualities and EER). Moreover, final SEM-based model depicting the relationship between SNSs and EER was also validated. The validity for both measurement and conceptual model is given in Table 5 .

The proposed relationship was represented by an arrow directing from SNSs qualities to EER for hypothesis 3. SEM-based models derive regression weight $(0.85)$ for the relationship and p-values less than 0.05 , which proves that relationship is significant. Therefore, the relationship between SNSs qualities and EER was accepted.

$\mathrm{R}^{2}$ value (0.79) of SEM model showed that, there is $79 \%$ variance because of SNSs qualities in EER. The results are given in Table 6. All the relationships were statistically significant, so can be accepted as well. The correlation between SNSs qualities and EER, and their proposed relationship results can be seen in Table 6 and Table 7. 
Table 6. Correlation Analysis

\begin{tabular}{|c|c|c|c|c|c|c|c|c|c|c|}
\hline Variables & EON & SEC & IQ & POP & NET & ERC & ERO & ERT & ERS & TGO \\
\hline EON & 1 & & & & & & & & & \\
\hline SEC & .899 & 1 & & & & & & & & \\
\hline IQ & $.938^{* *}$ & $.938^{* *}$ & 1 & & & & & & & \\
\hline POP & -.007 & -.115 & -.004 & 1 & & & & & & \\
\hline NET & -.014 & -.113 & -.005 & $.993^{* *}$ & 1 & & & & & \\
\hline ERC & $.286^{* *}$ & -.025 & .046 & $.353^{* *}$ & $.352^{* *}$ & 1 & & & & \\
\hline ERO & .027 & -.096 & .014 & $.837^{* *}$ & $.790^{* *}$ & $.273^{* *}$ & 1 & & & \\
\hline ERT & .115 & .098 & .141 & $.465^{* *}$ & $.461^{* *}$ & $.232^{* *}$ & $.424^{* *}$ & 1 & & \\
\hline ERS & -.029 & .047 & .011 & $.170^{*}$ & .153 & $.184^{*}$ & $.162^{*}$ & $.727^{* *}$ & 1 & \\
\hline TGO & $.941^{* *}$ & $.953^{* *}$ & $.966^{* *}$ & -.009 & -.014 & .050 & .013 & $.178^{*}$ & .133 & 1 \\
\hline
\end{tabular}

Table 7. Results of hypothesis

\begin{tabular}{|c|c|c|c|}
\hline Hypotheses & $\begin{array}{c}\text { Standardized } \\
\text { regression } \\
\text { weights }\end{array}$ & p-Value & $\begin{array}{l}\text { Statistical } \\
\text { results }\end{array}$ \\
\hline H3: A SNSs quality has direct significant effect on EER. & 0.85 & $<0.001$ & Significant \\
\hline H4: A SNS with easy navigation is better for recruitment. & 0.76 & $<0.001$ & Significant \\
\hline H5: A SNS with secure processes is better for recruitment. & 0.69 & $<0.001$ & Significant \\
\hline H6: A SNS with eminence proficiency is better for recruitment. & 0.80 & $<0.001$ & Significant \\
\hline H7: A SNS having more candidates' attraction is better for recruitment. & 0.75 & $<0.001$ & Significant \\
\hline H8: A SNS with network expedition is better for recruitment. & 0.70 & $<0.001$ & Significant \\
\hline H9: E-recruitment with higher degree of effectiveness is measure by cost. & 0.81 & $<0.001$ & Significant \\
\hline $\begin{array}{l}\text { H10: E-recruitment with higher degree of effectiveness is measure by } \\
\text { opportunity. }\end{array}$ & 0.82 & $<0.001$ & Significant \\
\hline H11: E-recruitment with higher degree of effectiveness is measure by time. & 0.78 & $<0.001$ & Significant \\
\hline H12: E-recruitment with higher degree of effectiveness is measure by speed. & 0.73 & $<0.001$ & Significant \\
\hline $\begin{array}{l}\text { H13: E-recruitment with higher degree of effectiveness is measured by target } \\
\text { group direction. }\end{array}$ & 0.74 & $<0.001$ & Significant \\
\hline
\end{tabular}

\section{Discussion}

The word e-recruitment or social recruitment is itself innovative. The present study contributed a first impression to what point the exploit of SNSs leads to efficient e-recruitment in Pakistan. But there is still require for additional research. Because with the way of time tendency modify, these days 2 websites LinkedIn and Facebook are most well-known for effective e-recruitment in Pakistan, may be after some decay others sites effective for recruitment. Job related websites are increasingly used by organizations in order to acquire the needed employees, as this kind of recruitment is becoming one of the governing types of recruitment methods as jobseekers are shifting from offline to online career opportunities.

The final SEM-based model describe that two latent variables named eminence proficiency and process security effect on SNSs quality for better recruitment had the highest ratio of importance and cause maximum variance with wit $24 \%$ and $23 \%$ as shown in Table 7. It suggests that SNSs are not proficient to provide better service for recruitment. Previous 
studies show that eminent proficiency is one of the important SNSs feature for different purposes like education, medical and politics. Network expedition is also one of the important feature of SNSs that contributes to effective recruitment wit 19\% importance. Easy navigation and candidate's attraction have least importance wit $18 \%$ and $17 \%$ consecutively. The weighted importance of each factor contributing SNSs quality for recruitment is shown in Table 8.

The current study covers the six telecom companies of Pakistan but for future the researchers can covers more companies and also in diverse cities can be taken under thought to confirm the Impact of social media using on effective e-recruitment in Pakistan. Thus, it is necessary to conduct a longitudinal research in order to see modify over time. Thus, the entire idea of recruitment is in a wind of welcoming alters. Recruitment is appropriate more and more relationship and medium based movement. Therefore, E-recruitment has been emerged as the major source of recruitment in now days. This research validated the effectives of two major SNSs Facebook and LinkedIn in six telecom companies of Pakistan.

Table 8. Standardized regression weights and relative importance

\begin{tabular}{|l|c|c|}
\hline Latent and observed variables & $\begin{array}{c}\text { Standardized regression } \\
\text { weights }\end{array}$ & $\begin{array}{c}\text { Weights of relative importance } \\
\text { (\%) }\end{array}$ \\
\hline Easily Navigate & $\mathbf{0 . 7 5}$ & $\mathbf{1 8 . 1 0}$ \\
\hline Easy to Learn & 0.81 & 25.28 \\
\hline Skillful user of site & 0.73 & 26.43 \\
\hline Friendly user designed & 0.83 & 25.62 \\
\hline Show quick outcome & 0.77 & $\mathbf{2 2 . 4 0}$ \\
\hline Secure Process & $\mathbf{0 . 7 2}$ & 25.87 \\
\hline Protected against abuse & 0.74 & 26.43 \\
\hline Authorized User & 0.78 & 24.31 \\
\hline Secondary user protection & 0.80 & 23.39 \\
\hline Secure communication & 0.65 & $\mathbf{2 3 . 5 0}$ \\
\hline Eminence Proficiency & $\mathbf{0 . 7 8}$ & 20.10 \\
\hline Trustworthy & 0.82 & 21.71 \\
\hline Necessary information & 0.67 & 19.80 \\
\hline Quick and clear & 0.65 & 20.28 \\
\hline Updated & 0.81 & 18.11 \\
\hline Sufficient for needs & 0.68 & $\mathbf{1 7 . 3 5}$ \\
\hline Candidate's attraction to SNSs & $\mathbf{0 . 8 8}$ & 34.45 \\
\hline Popularity & 0.72 & 32.90 \\
\hline More registered users & 0.79 & 32.65 \\
\hline Discussed in media & 0.62 & $\mathbf{1 8 . 6 5}$ \\
\hline Networking Expedition & $\mathbf{0 . 8 2}$ & 28.40 \\
\hline Valuable & 0.92 & 29.38 \\
\hline Wide networking scope & 0.86 & 23.20 \\
\hline Wide range & 0.70 & 19.02 \\
\hline Effective networking & 0.69 & \\
\hline
\end{tabular}




\section{Managerial Implications, Limitations and Future Research Directions}

The present study has contribution to show the impact of social networking sites on effective e-recruitment on major telecommunications vendor companies of Pakistan. This research covers three parts first to ensure that either tradition recruitment still useful for recruitment or not in terms of ease of accessibility and rapidity of response. Secondly, there is a strong relationship between Effective e-recruitment and attributes of Social Networking Sites. Thirdly, Maximum Telecommunication Vendor companies in Pakistan prefer e-recruitment through Social Networking Site (SNS) such as Facebook over LinkedIn. All of the three have importance respectively. The result of this study can be

obliging for the managers to exploit effective way for recruitment process. It is often pressured by many observers that there is a require for managers to exploit more complicated system for recruitment process. In this context, the present study approaches to explore the impact of SNS on effective recruitment process. It's beneficial for the researchers to know that, Facebook is very well-liked site among people these days and it also became the tendency to use Facebook commonly in Pakistan. Although other business sites are also used by some people but commonly not everyone found of using this site. So, it's examined that professional sites are now going to be admired not just for entertainments but also for business orientations.

This research is mostly aspired at the telecom company's Pakistan in order to investigate the capabilities of social media be relevant to the traditional recruitment methods. So, this study is accomplished in order to demonstrate that social media can function as a recruitment method. However, this caused on occasion slight difficult as the obtained information by means of the research results needed to be understand for the entire overall Pakistan's recruitment system, whereas the respondents provided information based on their own perspective and field. Thus, some provided information throughout this research might be biased from a particular viewpoint in terms of the involved field or purpose.

This study was only distributed through two social media networks (Facebook and LinkedIn), and not distributed through other means, which relied on participating respondents to forward the survey through E-mail or other means. Naturally, this hindered the results to only those who use E-mail. Time constraint was also one of the major limitations of the study. Longitudinal studies can also give different results.

Recruiters who work with job boards on daily basis even mention a rather high risk on selection faults. Hence the fact that it might be concerning to research the future consequences and effects of the recruitment quality with respect to the increasing utilization of job related websites. But the recent study contributed a first overview to what point the employ of SNSs leads to effective e-recruitment. But there is still a need for additional research. According to the HR departments, Facebook is the most important SNS for recruitment in Pakistan at the moment. But is it only a tendency? Companies can alter their user manners and predilections over time. Further research should be carried out to discover how culture affects the applicant's choice of job search channel. In addition, barriers to use of social media for different organizational purposes could be investigated. This would have a positive outlook for the trends of recruitment. 


\section{Conclusion}

This study shows the effectiveness and clear shift in trends, moving from offline to online recruiting practices. Social media has played a considerable role in managing organizations, but companies that can afford to do so use special software, custom online human interaction methods and professional sites (Facebook). Fundamentally, social media has allowed employees and employers to connect for business reasons, in addition to allowing people to connect and communicate socially. Fortunately, most technically savvy people are aware of privacy options and the probable to only share posted information with people connected with them on the site. Innovative recruitment practices obviously bring original challenges, potentially connecting changes in corporate culture. The exploit of different online software to recruit people involves cultural and sociological transitions. Social media can really tender a solution for promoting the jobs also to people who are not actively seeking for career opportunities. Facebook for example has got over a million daily consumers in Pakistan, which is unbelievable. We can see the possible using for recruitment currently. Companies have tried to utilize Facebook in their recruiting and succeeded but still needed to investigate more.

In conclusion, the results show that the role of SNSs in recruitment becomes much more important and can work as effective tool for recruitment for Pakistan companies. HR departments make cautious steps and first experiences with these sites. Most of the organizations questioned make use of the business-oriented networking site LinkedIn but now tendency change professional site Facebook has much more importance these days. In addition, it becomes evident that in order to locate the right employees to fill up their vacancies, recruiters profit from the networking scope of these sites.

\section{References}

[1] N. B. Ellison, "Social network sites: Definition, history, and scholarship," Journal of computer-mediated Communication, vol. 13, pp. 210-230, 2007.

[2] M. Chung and J. Kim, "The Internet Information and Technology Research Directions based on the Fourth Industrial Revolution," KSII Transactions on Internet \& Information Systems, vol. 10, no. 3, pp. 1311-1320, 2016. Article (CrossRef Link)

[3] G. Eurostat, "per capita in PPS," European Commission, 2013.

[4] D. Brossard and D. A. Scheufele, "Science, new media, and the public," Science, vol. 339, pp. 40-41, 2013. Article (CrossRef Link)

[5] J. M. Ortman, V. A. Velkoff, and H. Hogan, "An aging nation: the older population in the United States," United States Census Bureau, Economics and Statistics Administration, US Department of Commerce, pp. 25-1140, 2014. Article (CrossRef Link)

[6] N. Allden and L. Harris, "Building a positive candidate experience: towards a networked model of e-recruitment," Journal of Business Strategy, vol. 34, pp. 36-47, 2013. Article (CrossRef Link)

[7] R. Doherty, "Getting social with recruitment," Strategic HR review, vol. 9, pp. 11-15, 2010. Article (CrossRef Link)

[8] Y. Melanthiou, F. Pavlou, and E. Constantinou, "The use of social network sites as an e-recruitment tool," Journal of Transnational Management, vol. 20, pp. 31-49, 2015. Article (CrossRef Link)

[9] D. W. Greening and D. B. Turban, "Corporate social performance as a competitive advantage in attracting a quality workforce," Business \& Society, vol. 39, pp. 254-280, 2000. Article (CrossRef Link)

[10] M. I. Subhani, S. Joseph, A. Osman, and S. A. Hasan, "Contribution of Linkedin on Recruitment and Selection," South Asian Journal of Management Sciences (SAJMS), Iqra University, vol. 6, pp. 23-34, 2012. Article (CrossRef Link) 
[11] M. Kivimäki, S. T. Nyberg, G. D. Batty, E. I. Fransson, K. Heikkilä, L. Alfredsson, et al., "Job strain as a risk factor for coronary heart disease: a collaborative meta-analysis of individual participant data," The Lancet, vol. 380, pp. 1491-1497, 2012. Article (CrossRef Link)

[12] M. Alf, "Social media in logistics: nice to have or a pre-requisite for success," Retrieved March, vol. 20, p. 2013, 2013.

[13] J. Binney, B. Burnett, G. Kordopatis, P. J. McMillan, S. Sharma, T. Zwitter, et al., "New distances to RAVE stars," Monthly Notices of the Royal Astronomical Society, vol. 437, pp. 351-370, 2014. Article (CrossRef Link)

[14] A. Du Plessis and H. Frederick, "Effectiveness of e-recruiting: empirical evidence from the Rosebank business cluster in Auckland, New Zealand," Science journal of business management, vol. 2012, pp. 1-21, 2012. Article (CrossRef Link)

[15] M. Hynninen, M. Valtonen, H. Markkanen, M. Vaara, P. Kuusela, I. Jousela, et al., "Interleukin 1 receptor antagonist and E-selectin concentrations: a comparison in patients with severe acute pancreatitis and severe sepsis," Journal of critical care, vol. 14, pp. 63-68, 1999. Article (CrossRef Link)

[16] S. Eisele, Online-Recruiting: Strategien, Instrumente, Perspektiven: AV Akademikerverlag, 2012.

[17] Y. Lee and K. A. Kozar, "Investigating the effect of website quality on e-business success: An analytic hierarchy process (AHP) approach," Decision support systems, vol. 42, pp. 1383-1401, 2006. Article (CrossRef Link)

[18]S. A. Madia, "Best practices for using social media as a recruitment strategy," Strategic HR Review, vol. 10, pp. 19-24, 2011. Article (CrossRef Link)

[19] H. S. Hwang, "The Influence of personality traits on the Facebook Addiction," KSII Transactions on Internet \& Information Systems, vol. 11, pp. 1032-1042, 2017. Article (CrossRef Link)

[20] S. Abel, "The role of social networking sites in recruitment: Results of a quantitative study among German companies," University of Twente, 2011. Article (CrossRef Link)

[21] J. P. Tong, V. G. Duffy, G. W. Cross, F. Tsung, and B. P. Yen, "Evaluating the industrial ergonomics of service quality for online recruitment websites," International Journal of Industrial Ergonomics, vol. 35, pp. 697-711, 2005. Article (CrossRef Link)

[22] H. J. Smith, S. J. Milberg, and S. J. Burke, "Information privacy: measuring individuals' concerns about organizational practices," MIS quarterly, vol. 20, pp. 167-196, 1996. Article (CrossRef Link)

[23] C. Dwyer, S. Hiltz, and K. Passerini, "Trust and privacy concern within social networking sites: A comparison of Facebook and MySpace," in Proc. of AMCIS 2007 proceedings, p. 339, 2007. Article (CrossRef Link)

[24] M. El Ouirdi, A. El Ouirdi, J. Segers, and I. Pais, "Technology adoption in employee recruitment: The case of social media in Central and Eastern Europe," Computers in human behavior, vol. 57, pp. 240-249, 2016. Article (CrossRef Link)

[25] K.-K. Chu, T.-C. Shen, and Y.-T. Hsia, "Measuring website popularity and raising designers' effort," in Proc. of Systems, Man and Cybernetics, 2004 IEEE International Conference on, pp. 4095-4099, 2004. Article (CrossRef Link)

[26] J. Q. Anderson and H. Rainie, "The future of social relations," Pew Internet \& American Life Project, 2010. Article (CrossRef Link)

[27] M. Giles, "A world of connections: A special report on social networking," Economist Newspaper, 2010.

[28] P. Kaur, "E-recruitment: A conceptual study," International Journal of Applied Research, vol. 1, pp. 78-82, 2015. Article (CrossRef Link)

[29] M. Isaac, B. Erickson, S. Quashie-Sam, and V. Timmer, "Transfer of knowledge on agroforestry management practices: the structure of farmer advice networks," Ecology and society, vol. 12, 2007. Article (CrossRef Link)

[30] J. Scott, "Social network analysis," Sage, 2017.

[31] S. Papakonstantinidis, "Social recruiting: Exploring the impact of social networking sites on digital natives’ occupational opportunities," Centre for Labour Market Studies, 2014.

Article (CrossRef Link) 
[32] L. Barber, "E-recruitment Developments," Institute for Employment Studies Brighton, 2006.

[33] S. Gupta and J. Pirsch, "The influence of a retailer's corporate social responsibility program on re-conceptualizing store image," Journal of retailing and consumer services, vol. 15, pp. 516-526, 2008. Article (CrossRef Link)

[34] A. King, K. Ward, P. O'connor, D. Green, Z. Tonkin, and J. Mahoney, "Adaptive management of an environmental watering event to enhance native fish spawning and recruitment," Freshwater biology, vol. 55, pp. 17-31, 2010. Article (CrossRef Link)

[35] T. Minton-Eversole, "E-Recruitment comes of age, survey says," HR Magazine, vol. 52, p. 34, 2007.

[36] J. R. Pin, M. Laorden, and I. Saenz-Diez, "Internet recruiting power: Opportunities and effectiveness," IESE Business School, 2001. Article (CrossRef Link)

[37] D. A. Abowitz and T. M. Toole, "Mixed method research: Fundamental issues of design, validity, and reliability in construction research," Journal of construction engineering and management, vol. 136, pp. 108-116, 2010. Article (CrossRef Link)

[38] P. Gill, K. Stewart, E. Treasure, and B. Chadwick, "Methods of data collection in qualitative research: interviews and focus groups," British dental journal, vol. 204, p. 291-295, 2008. Article (CrossRef Link)

[39] R. Likert, "A technique for the measurement of attitudes," Archives of psychology, 1932. Article (CrossRef Link)

[40] R. V. Gibbons, F. J. Landry, D. L. Blouch, D. L. Jones, F. K. Williams, C. R. Lucey, et al., "A comparison of physicians' and patients' attitudes toward pharmaceutical industry gifts," Journal of general internal medicine, vol. 13, pp. 151-154, 1998. Article (CrossRef Link)

[41] J. C. Nunnally, Psychometric theory, 1967. Article (CrossRef Link)

[42] R. B. Kline, "Convergence of structural equation modeling and multilevel modeling," na, 2011.

[43] B. Yazdani, A. Attafar, A. Shahin, and M. Kheradmandnia, "Infrastructure and core QM, human resource results and customer satisfaction: the case of Iranian auto-industry part suppliers," International Journal of Productivity and Quality Management, vol. 18, pp. 78-98, 2016. Article (CrossRef Link)

[44] J. Hulland, "Use of partial least squares (PLS) in strategic management research: A review of four recent studies," Strategic management journal, vol. 20, pp. 195-204, 1999. Article (CrossRef Link)

[45] D. Straub, M.-C. Boudreau, and D. Gefen, "Validation guidelines for IS positivist research," The Communications of the Association for Information Systems, vol. 13, p. 63, 2004. Article (CrossRef Link)

[46] S. W. O'Leary-Kelly and R. J. Vokurka, "The empirical assessment of construct validity," Journal of operations management, vol. 16, pp. 387-405, 1998. Article (CrossRef Link)

[47] I. Sila, "Examining the effects of contextual factors on TQM and performance through the lens of organizational theories: An empirical study," Journal of Operations management, vol. 25, pp. 83-109, 2007. Article (CrossRef Link)

[48] H. W. Marsh, J. R. Balla, and R. P. McDonald, "Goodness-of-fit indexes in confirmatory factor analysis: The effect of sample size," Psychological bulletin, vol. 103, p. 391, 1988. 


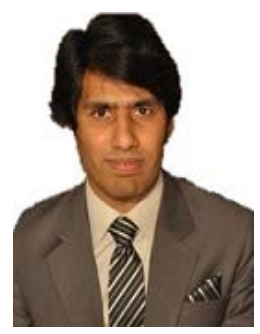

\begin{abstract}
Abdul Waheed is currently pursuing his $\mathrm{PhD}$ in Management Science and Engineering at the Northwestern Polytechnical University, Xi'an, China. He holds an MBA in Human Resource Management and Finance from the University of South Asia. His area of interest is human resource management and his major research topics covered are HRM practices, innovation performance, organizational performance and E-HRM.
\end{abstract}

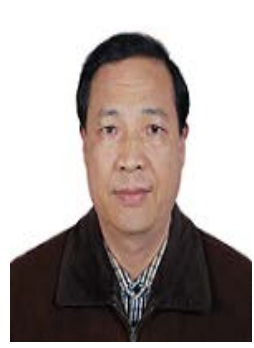

Miao Xiaoming has been working as a Lecturer, an Associate Professor and a Professor at the Northwestern Polytechnical University since July 1988 to present date. From June 2008 to 2009, he was a Visiting Scholar at the Utah State University and engaged in industrial economy research. From September 2003 to July 2007, he studied in School of Management of the Northwest Polytechnic University and received his Doctorate in Management Science and Engineering. His research focuses on technological innovation management, disruptive innovation, marketing, innovation performance and economics and trade.

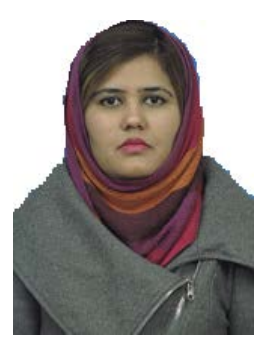

Salma Waheed is currently a PhD student in the school of Psychology, Shaanxi Normal University, Xi'an, China.. She has received her Master in Management Science and Engineering from the Northwestern Polytechnical University of Xian, China and another Master in Applied Psychology from the University of Punjab, Pakistan. Her areas of interest are human resource management, organization behavior, safety management, implementation of psychology theories like cognitive thinking and reasoning.

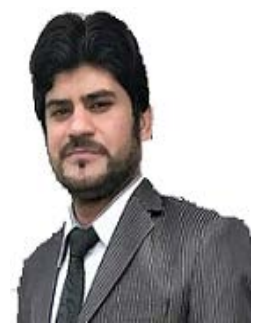

Naveed Ahmad is a PhD student in the School of Management, Northwestern Polytechnical University, Xi'an, China. He received his Master of Marketing from the Mohammad Ali Jinnah University. His areas of interest are marketing, HRM and sustainable development. His research covers different topics including internal marketing, organizational performance, marketing outcomes, brownfield redevelopment projects. 